\title{
O QUE SABEM E COMO ENSINAM OS PROFESSORES: INVESTIGANDO ESTRATÉGIAS PARA MUDANÇAS PARADIGMÁTICAS E DE ATITUDES ENFOCANDO A EDUCAÇÃO AMBIENTAL
}

\author{
Katarina Vasconcelos de Melo ${ }^{1}$ \\ Zélia Maria Soares Jófili ${ }^{2}$ \\ Ana Maria dos Anjos Carneiro-Leão ${ }^{3}$ \\ Gilvaneide Ferreira de Oliveira ${ }^{4}$
}

\section{RESUMO}

O objetivo deste estudo foi investigar a contribuição do uso de mapas conceituais, oficinas pedagógicas e entrevistas, no apoio à reflexão crítica dos professores sobre a sua prática pedagógica em Educação Ambiental, tendo como foco os ambientes recifais. A pesquisa foi desenvolvida numa Escola da Rede Pública de Ensino com três professores de Biologia. Os resultados evidenciam lacunas conceituais e dificuldades na articulação dos conceitos, bem como a percepção, pelos docentes, dos equívocos conceituais cometidos e, consequentemente, das próprias falhas na prática pedagógica. Ficou claramente estabelecida a necessidade de intervenções substanciais na formação docente para abalar as certezas sedimentadas por anos de ensino transmissivo numa visão disciplinar cartesiana e linear.

Palavras-chave: ambientes recifais, educação ambiental, formação docente, reflexão crítica.

\begin{abstract}
This study aimed to investigate the contribution of concept maps, pedagogical workshops and interviews ring teachers' development programs in the sense of promoting critical reflection about their own pedagogical practices, conceptual gaps and the fragmented view they have of Environmental Education disciplinary content, with special focus on reef environments. The study was carried out with three Biology teachers from a State School. The results show conceptual gaps and difficulties in articulating concepts as well as the perceptions, by the teachers, of the conceptual mistakes they had made and, consequently, the flaws in their own pedagogical practices. It was clear that there is a need to intervene substantially in teachers' initial and continuing education in order to affect the certainties cemented by years of transmissive teaching within a Cartesian and linear disciplinary viewpoint.
\end{abstract}

Keywords: reef environments, environmental education, teacher training, critical reflection.

\footnotetext{
${ }^{1}$ Bióloga, Mestre em Ensino de Ciências pelo PPGEC/UFRPE. Professora da SEDUC-PE. E-mail: katyvmelo@ig.com.br

${ }^{2}$ Doutora em Educação pela Surrey University (UK). Professora do PPGEC-UFRPE. E-mail: jofili@gmail.com

${ }^{3}$ Doutora em Bioquímica pela UFPR. Professora do DMFA-UFRPE. E-mail: amanjos50@ gmail.com

${ }^{4}$ Bióloga,Doutora em Educação pela Uma (Portugal). Professora do Dep. Educação-UFRPE. E-mail: gil@ ded.ufrpe.br
} 


\section{INTRODUÇÃO}

As discussões na mídia e no ambiente acadêmico sobre temas ambientais têm sido um tópico recorrente. São motivadas, nas últimas décadas, por alterações comportamentais em algumas espécies (como os ataques de tubarão no litoral de Pernambuco) ou alterações na biosfera (aquecimento global, rompimento na camada de ozônio) e em ecossistemas (extinção de espécies como o peixe boi, a tartaruga marinha, o mico leão dourado, entre outros). Estes fatos vêm chamando a atenção para a necessidade de conscientizar as pessoas sobre o impacto das ações humanas sobre o meio ambiente, seja quanto aos fatores bióticos, seja quanto aos fatores abióticos, pois ambos estão intimamente ligados (GOULART \& CALLISTO, 2003).

Segundo a Constituição Brasileira (BRASIL, 1988), é incumbência do Poder Público "promover a educação ambiental em todos os níveis de ensino e a conscientização pública para preservação do meio ambiente" (Inciso VI do Capítulo VI - Art. 225). No entanto, as ações de educação ambiental (EA) não parecem estar promovendo essa conscientização, nem as medidas tomadas para a proteção da fauna e flora estão sendo eficazes para proteger os ambientes recifais.

A forma como a EA vem sendo praticada nas escolas e junto à população em geral é um reflexo da pouca clareza sobre o assunto. Os conteúdos trabalhados são pouco articulados, o que desfavorece uma sensibilização ou mesmo uma mudança de postura diante das questões ambientais. Este fato aponta para o despreparo do corpo docente para desenvolver nos estudantes, além de conhecimentos, sensibilidade, valores e atitudes relacionados a uma EA sustentável. Associado a este problema está a fragmentação do conhecimento dentro de uma matriz curricular tradicionalista que privilegia conhecimentos teóricos, abstratos e informativos, com disciplinas desarticuladas entre si e desvinculadas de problemas concretos que envolvam o meio natural e social (OLIVA, 2002).

Estes dados nos remetem a pensar uma formação docente que transcenda o mero processo informativo e busque o desenvolvimento de atitudes. Para isso, o professor precisa conhecer de forma profunda e sistêmica o conteúdo que está trabalhando em sala de aula e refletir sobre o mesmo, a fim de alcançar práticas pedagógicas emancipatórias.

A introdução, no sistema educativo, da dimensão ambiental voltada aos ambientes recifais exige um novo modelo de professor e sua formação é a chave para a mudança que se propõe, tanto pelos novos papeis que os professores terão que desempenhar no seu trabalho, como pela necessidade de que sejam agentes transformadores de sua própria prática (MEDINA e SANTOS, 1999). A formação continuada favorece a busca de conhecimento para manter o docente atualizado, visando a construção e o desenvolvimento das competências exigidas para o exercício profissonal.

Este estudo se propõe, portanto, a investigar no contexto de uma formação continuada, as contribuições de entrevistas, aula de campo e construção individual e coletiva de mapas, para a reflexão dos docentes sobre o seu saber disciplinar e sua prática pedagógica e a repercussão dessas atividades na compreensão conceitual e na mudança na prática pedagógica dos professores envolvidos.

\section{EDUCAÇÃO AMBIENTAL}

Dentre as diversas nomenclaturas algumas foram selecionadas para, neste estudo, alocar as definições, conceituações ou representações assumidas pelos professores entrevistados sobre os significados que têm, para eles, a EA e como se traduzem em práticas 
docentes. São elas a naturalista, com suas subdivisões e a socioambiental, representando o conjunto das teorias críticas.

Segundo Carvalho (2004), uma das visões sobre a natureza que reflete no desenvolvimento da EA é a chamada naturalista. Esta perspectiva toma por base a percepção da natureza como fenômeno estritamente biológico, onde as interações ecossistêmicas seguem de maneira autônoma e independente da interação com o mundo cultural humano. Associa-se a esta ideia, a compreensão de um mundo natural constituído em oposição ao mundo humano. $\mathrm{Na}$ visão naturalista, a natureza é compreendida como tudo aquilo que deveria permanecer fora do alcance do ser humano. Tal concepção é fortalecida, principalmente, pelas orientações preservacionistas, que se dedicam a proteger a natureza das interferências humanas, entendidas sempre como ameaçadoras à sua integridade.

\section{Buscando superar a dicotomia natureza-sociedade, a visão socioambiental}

[...] orienta-se por uma racionalidade complexa e interdisciplinar e pensa o meio ambiente não como sinônimo de natureza intocada, mas como um campo de interações entre a cultura, a sociedade e a base física e biológica dos processos vitais, no qual todos os termos dessa relação se modificam dinâmica e mutuamente (CARVALHO, 2004, p. 37).

Loureiro et al. (2011) destacam que os educadores não podem ser pessoas preocupadas exclusivamente com a "natureza", incapazes de enxergar as complexidades, dificuldades e crises do mundo a sua volta. A EA deve ter como preocupação proteger não só as águas, o ar, a flora e a fauna, mas também os seres humanos. Esses muitas vezes reúnem todas as características que os tornam mais susceptíveis à injustiça ambiental - miséria, pobreza, situação de risco em todos os sentidos e, principalmente, falta de informação, tornando-se muitas vezes vítimas e algozes de seu entorno. A distinção entre homem e natureza compromete a compreensão do que é meio ambiente, reduzindo o conceito à dimensão naturalista. Essa dimensão acaba por desconsiderar os aspectos sociais, econômicos e urbanos do meio ambiente, e tal dificuldade interpretativa pode, entre outras razões, estar associada à influência da epistemologia cartesiana.

No que se refere à prática pedagógica em EA, Guimarães (2004) pontua a EA conservadora que, em contraponto à crítica, se fundamenta no cientificismo cartesiano e no antropocentrismo. Isso produz uma prática pedagógica objetivada no indivíduo (na parte) e na transformação de seu comportamento (educação individualista e comportamentalista). Essa é uma forma simplista e reduzida de perceber uma realidade complexa que vai além da soma das partes. Não contempla a perspectiva de a educação se realizar no movimento de transformação do indivíduo inserido num processo coletivo de transformação da realidade socioambiental como uma totalidade dialética em sua complexidade. Não compreende que a educação é relação que se dá no processo e não, simplesmente, no sucesso da mudança comportamental de um indivíduo.

Desta forma, uma prática de EA conservadora (ou tradicional) reflete os paradigmas da sociedade moderna que privilegia o aspecto cognitivo do processo pedagógico, acreditando que "transmitir" o conhecimento correto fará com que o indivíduo compreenda a problemática ambiental e, com isso, transforme seu comportamento e, consequentemente, o da sociedade.

Por este motivo, apesar do crescente número de projetos e trabalhos desenvolvidos nas escolas, tanto na educação formal quanto na não formal, tem-se observado um aumento na degradação ambiental (GUIMARÃES, 2004). Isto sugere que apenas a difusão de informações e/ou trabalhos desenvolvidos de forma específica como a questão do lixo, por exemplo, não são suficientes para instigar a sociedade para a mudança de hábitos e valores. 
Segundo Behrens (1999), o paradigma inovador é sistêmico e tem como pressuposto uma prática pedagógica que possibilite a produção do conhecimento. Essa dimensão sistêmica pretende que o homem recupere a visão do todo, que se sinta pleno, vivendo dentro da sociedade como um cidadão do mundo e não como um ser isolado em sua própria individualidade. A maior dificuldade em redimensionar as instituições de ensino nessa nova abordagem é justamente superar a visão fragmentada que se instituiu com o positivismo no processo pedagógico (BEHRENS, 2005). O grande desafio da visão holística é a superação do saber fragmentado, uma vez que este, nas escolas, foi dividido em disciplinas isoladas, assemelhando-se ao trabalho nas indústrias que se tornou especializado e repartido em setores. Por consequência, os homens passaram, na escola e no trabalho, a se restringir a tarefas estanques, sem a consciência global do processo e do produto a ser produzido.

É reconhecível e evidente a dificuldade em pensarmos de forma sistêmica. Capra (1996) exemplifica, mencionando aqueles que afirmam que a essência da vida está nas macromoléculas, no DNA, nas proteínas e nas enzimas, quando a teoria dos sistemas vivos diz que a essência não está nas moléculas, mas sim nos padrões e processos por meio dos quais essas moléculas interagem. Sabendo que os sistemas vivos estão baseados em padrões de relacionamento é preciso uma nova maneira de ver e de pensar em termos de relações, conexões e contextos, e essa forma de pensar envolve várias mudanças.

O novo paradigma concebe o mundo como um todo integrado, e não como uma coleção de partes dissociadas. Dessa forma, estamos todos encaixados nos processos cíclicos da natureza. O ser humano é um finíssimo fio dessa rede universal denominada "teia da vida" e a característica mais nítida de qualquer rede é a sua não linearidade (CAPRA, 1996).

Sendo assim, a prática docente dos professores foi analisada segundo os parâmetros da pedagogia conservadora (tradicional) e da inovadora (BEHRENS, 1999), numa vertente crítica e sistêmica ${ }^{5}$.

\section{OS AMBIENTES RECIFAIS COMO FOCO DE ESTUDO}

Neste trabalho, optamos por estudar os ambientes recifais, ecossistemas ricos em recursos naturais de grande importância ecológica, uma vez que proporcionam habitat adequado para o desenvolvimento da fauna e da flora marinha. Isto se deve às condições de iluminação, de transparência da água, de salinidade, de temperatura, do $\mathrm{pH}$ e da alta produtividade biológica e econômica. Portanto, esses ambientes suportam e abrigam uma variedade de comunidades marinhas de interesse econômico direto, como peixes, polvos, lagostas e camarões, entre outros.

Os ecossistemas recifais são estruturas compostas por carbonato de cálcio. Os seus principais formadores são a alga calcária melobesiácea, o banco de arenito (areia) e o animal coral. Estes são auxiliados pelos animais perfuradores como, por exemplo, o ouriço, as esponjas, os anelídeos poliquetas e os moluscos bivalves. É importante destacar que a produtividade primária proveniente destes ambientes deve-se à relação simbiótica que ocorre entre a alga zooxantela e o animal coral. A zooxantela, ao receber a energia do sol, realiza o processo fotossintético e, através do mesmo, libera para o coral, oxigênio e compostos orgânicos. O coral, ao mesmo tempo, libera para a zooxantela: dióxido de carbono, fósforo, compostos nitrogenados e amônia (BARNNES, 1996).

Por toda a produtividade existente, estes ecossistemas são riquíssimos em sua biodiversidade marinha e, decorrente deste fator, vêm ganhando destaque no mercado, pois

${ }^{5}$ Para melhor entender as vertentes crítica e sistêmica ver Carvalho (2004), Guimarães (2004) e Capra (2006). 
neles encontram-se organismos com propriedades na farmacologia, na medicina, na odontologia, na indústria de cosméticos, em atividades artesanais, além de atuarem naturalmente como um fator de proteção natural à costa, evitando assim, o avanço do mar (AMARAL et al.2002a e b; AMARAL et al. 2003). Além das propriedades citadas, estes ambientes oferecem uma das particularidades mais importantes para a vida, pois o oxigênio que respiramos vem dos mares.

O aumento de turistas locais, a utilização desordenada e mal planejada das atividades turísticas e o uso de artefatos tecnológicos, podem causar uma série de danos a esses ambientes naturais (MELO et al. 2005). Podemos salientar algumas consequências desse turismo exploratório, como por exemplo, a prática do mergulho, da ancoragem e do pisoteio. A prática do mergulho é classificada como um impacto direto, pois causa danos físicos aos recifes, ou seja, quebra, rompe e lesa os corais. Além disso, os turistas, ao alimentarem os animais, estão interferindo nos seus hábitos alimentares e comportamentais, fazendo-os perder sua habilidade de procurar comida, o que pode afetar o tamanho das populações e mudar os comportamentos naturais. A pesca e a coleta de organismos também contribuem para o empobrecimento biológico e genético do ecossistema, pois sendo praticadas de forma predatória causam o declínio nos estoques pesqueiros. A ancoragem dos barcos nos recifes pode causar impactos severos e é proporcional ao tamanho dos barcos e ao peso da âncora no substrato sobre o qual ela está assentada (MELO et al. 2005).

Quanto aos impactos indiretos podemos mencionar a construção de portos, marinas, hoteis e outras instalações integrantes do setor turístico que contribuem para a degradação dos recifes através do despejo de esgotos, sem tratamento, nas águas costeiras. Este despejo favorece o enriquecimento de nutrientes, o que provoca a proliferação de algas que atuarão como competidoras dos corais pelo ambiente e pela oxigenação (MELO et al. 2005).

\section{A REFLEXÃO CRÍTICA SOBRE A PRÁTICA PEDAGÓGICA COMO ESTRATÉGIA NA FORMAÇÃO CONTINUADA}

A reflexão crítica sobre a compreensão sistêmica dos conteúdos e a prática pedagógica usual relaciona-se à necessidade do professor desenvolver práticas pedagógicas mais efetivas e estratégias inovadoras de ensino. A postura crítica e reflexiva diante das problemáticas concernentes ao contexto ambiental deverá oportunizar aos educandos sensibilização, mobilização e, até mesmo, mudança de atitude diante desses ambientes, ao longo do tempo.

Para Freire (1996) a prática docente crítica, implicante do pensar certo, envolve o movimento dinâmico, dialético, entre o fazer e o pensar sobre o fazer. Na formação permanente dos professores, o momento fundamental é o da reflexão crítica sobre sua prática. Segundo ele é pensando criticamente a prática de hoje ou de ontem que se pode melhorar a próxima prática. Portanto, cabe ao professor justamente essa mudança de postura diante de uma nova forma de compreender o mundo e na sua prática pedagógica.

O ensino crítico envolve mudança conceitual e esse tipo de mudança não corresponde a situações lineares onde ocorre uma mera substituição de situações velhas por novas. Envolve sim, situações complexas, multifacetadas e que não são facilmente resolvidas. Nesse caso, a necessidade de reestruturação ou reconstrução do pensamento, evolui de estados pessoais ou subjetivos, exigindo mudanças para que ocorram. Mudar a forma de pensar em questões profissionais exige imensa flexibilidade e pensamento crítico por parte dos professores. O diálogo crítico é pré-requisito indispensável para um ensino crítico construtivista e para que o pensamento crítico possa ser desenvolvido. Refletir criticamente sobre a própria prática tornará possível a percepção dos erros cometidos, as interferências 
ideológicas e os obstáculos ao processo de aprendizagem. A condição para tudo isso ocorrer é a existência de uma liderança democrática, consciente, curiosa, receptiva e cientificamente competente (JÓFILI, 2006).

Segundo Nóvoa (1995), a formação deve alicerçar-se numa reflexão sobre a prática através de dinâmicas de investigação-ação e de investigação-formação, valorizando os saberes de que os professores são portadores. Contudo, trabalhar a formação continuada visando uma prática pedagógica emancipatória em EA ainda é difícil, visto que há uma resistência muito grande por parte do professorado. Esses a percebem apenas como "preservação da natureza" e a trabalham de forma linear e desarticulada focando, principalmente, a "transmissão" de conhecimentos. Segundo muitos profissionais, essa falha deve-se realmente à falta de embasamento teórico para tratar destas questões (BONOTO et al. 2002).

As Oficinas Pedagógicas (OP) são de extrema utilidade para a compreensão de conteúdos complexos e abstratos, possibilitando integrar teoria e prática. Ao aliar a ação e a reflexão durante o seu desenvolvimento, favorecem o aprofundamento conceitual dos participantes quanto à percepção das próprias lacunas no conhecimento científico e a avaliação da adequação de sua prática docente para a aprendizagem de seus alunos (CARNEIRO-LEÃO et al., 2009).

\section{METODOLOGIA}

A investigação foi realizada numa escola da rede pública estadual de ensino e está inserida numa comunidade de classe média baixa, atendendo 955 alunos distribuídos em três turnos, dentro da modalidade de ensino de Educação de Jovens e Adultos - EJA. Deste estudo participaram três (3) docentes de Biologia, referidos por D1, D2 e D3 com experiência de ensino entre 5 e17 anos.

Para identificarmos as concepções e percepções dos docentes em relação à EA e aos ambientes recifais, optamos pela entrevista semi-estruturada. A entrevista, gravada em áudio, teve a função, também, de coletar dados acerca de como planejam/estruturam suas aulas focadas nesse conteúdo. Na sequência, foi proposta uma Oficina pedagógica em que foram desenvolvidas as seguintes atividades: (1) construção individual de mapas conceituais (MC), individualmente. pelos participantes, abordando os ambientes recifais; (2) aula de campo interventiva; e (3) reconstrução coletiva dos MC individuais.

Os MC foram construídos em parking lot ${ }^{6}$, segundo Novak e Cañas (2010). Tiveram como ponto de partida uma relação de conceitos oferecida aos sujeitos, para serem utilizados (ou não) na elaboração do $\mathrm{MC}$, que respondesse à questão norteadora: "O que você entende por um ecossistema recifal?" Os conceitos apresentados na forma de palavras-chave (termos) ou ilustrações funcionaram como ponto de partida para a elaboração dos MC individuais, oferecendo informações sobre as dificuldades dos pesquisados, pois os conceitos não integrados ao MC sugerem dificuldades na sua compreensão e articulação. Para a construção dos mapas foram entregues aos três professores kits compostos por: 43 palavras-chave; três cartas brancas (coringas); nove imagens; folhas de cartolina, cola e lápis hidrocor. Os conceitos utilizados no mapa foram extraídos de Amaral et al. (2003) e Ruppert e Barnes (1996).

A aula de campo propiciou uma vivência nos ambientes recifais das praias de Tamandaré e Carneiros, litoral sul de Pernambuco. Inicialmente foi proposto o seguinte problema: "Com a extinção do fitoplâncton nos mares o que poderá acontecer aos ambientes

6 Um mapa conceitual construído em parking lot (ou "estacionamento de conceitos") disponibiliza aos autores uma relação de conceitos, que podem ou não ser utilizados (Conforme NOVAK e CAÑAS, 2010). 
recifais e à atmosfera?" A partir daí teve início a discussão com os esclarecimentos necessários relativos ao tema. Durante a aula foram realizadas as seguintes atividades: reconhecimento de um ambiente recifal, sua estrutura, o tipo de recife, sua formação e sua biodiversidade; contato direto com alguns organismos, a exemplo de ouriços, esponjas marinhas, cracas, ascídias, caranguejos; constatação dos impactos sofridos (lixo lançado no mar: sacos plásticos, garrafas, etc.; aluguel de barcos e lanchas para passeio aos recifes, construção de pousadas e bangalôs, entre outros fatores); e a observação de exemplares do coral vivo e morto da espécie Siderastrea stellata Verrill 1868.

A entrevista final buscou investigar a compreensão sistêmica do conteúdo específico ambientes recifais, seja (a) pela construção dos MC (individuais e coletivo) ou (b) pela participação na aula de campo; a percepção dos professores quanto à coerência (ou não) da sua prática docente usual, visando uma aprendizagem significativa e sistêmica de seus alunos; e a intenção, ao menos em nível de discurso, de modificar a sua prática em sala de aula, aplicando as estratégias vivenciadas.

\section{RESULTADOS E DISCUSSÃO}

Os resultados foram organizados em três momentos, considerando-se as etapas vivenciadas cronologicamente na metodologia, ou seja: (a) entrevista inicial; (b) oficina pedagógica em que foram construídos mapas conceituais pelos participantes em duas etapas (inicial e final, respectivamente), bem como vivenciada aula de campo em que foram observados os ambientes recifais in loco; e (c) entrevista final. Para a análise dos dados foram construídas categorias a partir dos resultados obtidos em cada etapa.

\section{ENTREVISTA INICIAL}

Por intermédio da análise das questões da entrevista inicial, pudemos compreender como os docentes percebem os ambientes recifais, como planejam as aulas focadas nesses ambientes e, se compreendem ou não, de forma articulada, os conceitos envolvidos nesse conteúdo. Com relação à percepção dos ambientes recifais, foram criadas as seguintes categorias para analisar as respostas dos professores:

Preservacionista/naturalista: respostas que apresentam o meio ambiente como estritamente biológico e cujas interações não envolvem o ser humano (LOUREIRO, 2004).

Conservacionista: respostas que pontuam a conservação dos recursos naturais, visando prevenir a escassez (SORRENTINO, 2002).

Socioambiental: respostas que representam o conjunto das teorias críticas (CARVALHO, 2004; LOUREIRO, 2011), mas que não foram detectadas neste estudo.

No que se refere à prática pedagógica dos pesquisados foram utilizadas as seguintes categorias para analisar suas respostas:

Conservadora: respostas que apresentam práticas pedagógicas tradicionais de ensinoaprendizagem, que não superam o positivismo e o cartesianismo, privilegiando a fragmentação (GUIMARÃES, 2004).

Crítica: respostas que apresentam práticas pedagógicas crítico-construtivistas (FREIRE, 1996; JÓFILI, 2006 ), mas que não foram detectadas neste estudo.

Senso comum: respostas inconsistentes. 
Finalmente, para analisar a compreensão dos pesquisados sobre a importância dos ambientes recifais; os formadores responsáveis por estes ambientes; as ações antrópicas diretas e indiretas e suas consequências sobre os ambientes recifais, foram criadas as seguintes categorias, amparadas em Ruppert e Barnes (1996) e nos estudos de Amaral et al. (2003; 2006):

quanto à importância dos ecossistemas - ecológica, farmacológica e econômica;

quanto aos formadores dos ambientes recifais - corais, algas calcárias e banco de arenito;

quanto às ações antrópicas diretas - poluição por lixo doméstico (resíduo sólido); lançamento de petróleo; lançamento de metais pesados advindos das indústrias; ações agrícolas; desmatamento; pesca predatória, etc.

quanto às ações antrópicas indiretas - industrialização; consumo exagerado; exploração dos recursos naturais, etc.

\section{ANÁLISE DAS QUESTÕES RELACIONADAS ÀS CONCEPÇÕES DE EA E DE ECOSSISTEMAS RECIFAIS E A PERCEPÇÃO DA DISCIPLINA DE EA}

As respostas de todos os professores situam-se dentro de uma visão naturalista (antropocêntrica/utilitarista) voltada para a preservação do meio. Ao homem é atribuída a responsabilidade pela degradação e, à disciplina de Educação Ambiental, cabe a responsabilidade de reverter este quadro através da conscientização da população (e dos alunos em particular) de como deve ser cuidado o ambiente em que vivem (D1) e mudando os conceitos sobre meio ambiente transformando as ideias em ações (D2). No entanto, outro professor pontua:

[...] em relação à disciplina ela só fica mesmo dentro da sala de aula [...] basicamente é mais conteúdo e aí a gente não leva a prática para os alunos para terem uma visão melhor de determinado assunto (D3).

Reigota (2002) rebate a ideia, muito disseminada, de que através da conscientização as pessoas mudam os seus hábitos e comportamentos, considerando:

Creio que qualquer pessoa com um mínimo de informação sabe dos malefícios produzidos pelo cigarro, no entanto, vemos professores, médicos, ecologistas, engenheiros etc. fumando. Quero dizer com isso que, se a informação, a conscientização e o conhecimento científico fossem suficientes para a mudança de hábitos e comportamentos, essas pessoas não fumariam (p. 145).

Com relação ao entendimento que possuem sobre ambientes recifais, as respostas foram evasivas, permanecendo no senso comum, como exemplificado pela resposta de D3:

Em relação aos ambientes recifais, o conhecimento que eu tenho, são os corais. É um ecossistema marinho que vem sendo muito degradado pelo ser humano (D3).

\section{ANÁLISE DAS QUESTÕES RELACIONADAS ÀS PRÁTICAS DE EA E À PRÁTICA PEDAGÓGICA - FINALIDADES DA DISCIPLINA EA E COMO TRABALHAM O TEMA AMBIENTES RECIFAIS.}


Quanto à prática de EA, todos os professores se enquadraram numa visão naturalista de preservar o meio ambiente através de ações pontuais, enfatizando a coleta do lixo, como pode ser observado no excerto da entrevista a seguir:

A educação ambiental eu pratico pensando em fazer as coisas certas. Usando com consciência o que o ambiente e o que o progresso nos oferecem. Por exemplo, economizando água, economizando energia, botando o lixo no lugar certo, etc. (D1).

Perguntados sobre como conduziriam uma aula abordando o tema ambientes recifais as respostas denunciam uma prática tradicional com ênfase na transmissão de informações pontuais, fragmentadas e desarticuladas. Apesar de enfatizarem a importância desses ambientes, não problematizam, não relacionam os conceitos de um ecossistema em funcionamento com as ações do homem e suas possíveis consequências sobre ele mesmo e sobre o ecossistema.

No primeiro momento eu explicaria o que é o recife, qual a sua importância, onde podemos encontrá-lo e suas características. $O$ ponto mais importante seriam as especificações, suas características, importância para o meio ambiente e para o ser humano (D3).

Finalmente, quanto aos recursos, estes teriam apenas a função de apoiar uma prática transmissiva, como pode ser constatado nos depoimentos a seguir:

Eu usaria cartazes, fotos, imagens e tentaria mostrar algum filme, algum vídeo que mostrasse esse ambiente (D3).

Este tipo de ensino promove situações que não desenvolvem no educando a compreensão, a reflexão, a resolução de problemas e a articulação de conceitos. Ao serem condicionados apenas a decorar para passar nos testes têm a sua passividade agudizada, reforçando a condição de meros receptores de informações.

Quanto à importância que atribuem aos ambientes recifais, alocamos as respostas em três categorias:

Ecológica: quando os ambientes recifais são considerados como abrigo e berçário de vários animais marinhos; importantes para o equilíbrio e manutenção do ecossistema, da cadeia alimentar e das relações ecológicas; e ao proporcionar maior quantidade de oxigênio para a atmosfera.

Econômica: quando se refere à produtividade marinha (alimentar); extração de produtos para produção de cimento; extração de produtos cosméticos e adornos como colares, entre outras.

Médica: quando se refere à extração de produtos para a cura do câncer e da AIDS; extração de substâncias para a reparação de fraturas e para reparação odontológica, etc.

Dois docentes (D1 e D2) responderam de forma incompleta, enfatizando apenas a categoria ecológica. O docente D3 citou duas categorias (ecológica e econômica) e sua resposta foi considerada parcialmente completa. Quanto à importância econômica demonstrou uma visão utilitarista enfatizando a questão financeira.

Como os principais formadores dos ambientes recifais, foram considerados: coral, alga calcária melobesiácea e banco de arenito. Os três professores se referiram apenas aos corais e, portanto, suas respostas foram enquadradas como incompletas, o que denuncia uma lacuna conceitual bem evidente. 
Com relação às agressões antrópicas diretas e indiretas que os corais vêm recebendo, foram consideradas as ações diretas (poluição por lixo doméstico; lançamento de petróleo; lançamento de metais pesados advindos das indústrias; ações agrícolas; desmatamento; pesca predatória, etc.) e as ações indiretas (industrialização; consumo exagerado; exploração dos recursos naturais, entre outros).

Os docentes apenas destacaram ações que podem ser visualizadas diretamente. D1, mesmo sem distinguir a ação direta da indireta (já que para ele ambas são diretas porque qualquer que seja a agressão do homem ela é direta) se contradisse ao salientar que "a medida que a gente contribui para o aquecimento global aumentando a temperatura dos mares, a contribuição é direta. Nós vamos trabalhando e agredindo cada vez mais diretamente".

Estes resultados indicam que o docente não diferencia, de fato, ações diretas e indiretas, pois pontua que contribuímos para o aquecimento global aumentando a temperatura dos mares de forma direta. Ora, se contribuímos, ela já não é direta, de fato é indireta e, ao colaborarmos de alguma forma, agravamos a situação.

D2 e D3 apresentaram conhecimento do senso comum, como se as únicas agressões fossem as diretas, como a questão do lixo (lançamento de resíduos), por exemplo. Sabemos que as agressões, em sua maioria, não são visíveis diretamente e, muitas vezes, não se tem a noção de o quanto estamos afetando o meio porque não refletimos sobre nossas ações. Estas respostas nos permitem identificar concepções fragmentadas e imensas lacunas conceituais entre os docentes: lacunas conceituais pela não distinção entre as ações diretas e indiretas; e, fragmentação, por não conseguirem estabelecer relações entre as ações diretas e indiretas. Finalmente, as respostas evidenciam que nenhum dos professores tinha visto, anteriormente, um coral total ou parcialmente branqueado (morto).

\section{MAPAS CONCEITUAIS INDIVIDUAIS DOS DOCENTES}

Durante a formação continuada realizada nesta pesquisa foram construídos dois mapas individuais pelos três participantes da oficina pedagógica. $\mathrm{Na}$ análise desses mapas, registramos que nenhum deles conseguiu relacionar as trocas gasosas nem a relação desses gases com os demais componentes bióticos. Constatamos, também, evidente dificuldade na articulação dos conceitos envolvidos no estudo do ecossistema recifal. Um fato importante a ser ressaltado refere-se à questão de que os professores igualmente não inseriram o homem como componente biótico participante do meio ambiente. Relatam que o homem não faz parte desse ecossistema, não participa do ciclo biológico (cadeia alimentar, trocas gasosas, etc.) e é analisado apenas como um "sujeito prejudicial" ao meio ambiente, do qual apenas extrai os benefícios oportunizados.

Quando eu coloquei o homem, ele está relacionado a sistema biótico... tá dentro dele [...] tá destruindo ou até mesmo fazendo parte do componente biótico... eu pensei mais na forma de destruição, na degradação desse ambiente (D3).

A análise dos mapas quanto à relação entre os componentes bióticos e abióticos, evidenciou que nenhum dos professores estabeleceu relação entre eles apontando-os separadamente, embora tenham ocorrido algumas tentativas de ligações. É relevante registrar que nenhum deles conseguiu relacionar nem as trocas dos gases nem a relação destas com os demais componentes bióticos, embora seja conhecido que a entrada e a saída de gases provenientes da relação simbiótica entre o coral e a zooxantela se distribui e se amplia para todas as instâncias do ecossistema, chegando ao homem. 


\section{AULA DE CAMPO - VIVÊNCIA NOS AMBIENTES RECIFAIS DE TAMANDARÉ E} CARNEIROS

Inicialmente foi proposto um problema: Com a extinção do fitoplâncton nos mares o que poderá acontecer aos ambientes recifais e à atmosfera? A partir dessa problematização, iniciou-se a discussão e foram feitos os esclarecimentos necessários.

Os pesquisados apontaram como consequência da extinção do fitoplâncton, a escassez de alimento e do oxigênio, sem relacionar essas ocorrências ao desequilíbrio da cadeia alimentar, à quebra da cadeia, ao aumento de $\mathrm{CO}_{2}$ e à morte do coral, sendo que todos estes fatores são prejudiciais, inclusive para o próprio homem. Além disso, não mencionaram os inúmeros benefícios oportunizados por esses ambientes como o controle do clima, a diminuição do $\mathrm{CO}_{2}$ e a extração de substâncias para a cura de algumas doenças.

Apesar das dificuldades detectadas nos docentes em relacionar os conceitos, compreendê-los de forma sistêmica e até mesmo, ignorá-los, a aula de campo oportunizou viver e sentir, de forma concreta, os ambientes recifais e instigou sua percepção e reflexão acerca desses ambientes. Os professores tiveram oportunidade de conhecer corais vivos e mortos, bem como outros habitantes destes ecossistemas, o tipo de recife, a importância ecológica e econômica que provém dos mesmos e observar as ações antrópicas sobre o ecossistema tanto na Praia de Tamandaré quanto na Praia dos Carneiros.

\section{MAPA CONCEITUAL COLETIVO}

O Mapa Conceitual Coletivo dos Docentes foi construído de forma colaborativa ao final da Oficina Pedagógica.

Nessa construção, diferentemente do que ocorreu no desenvolvimento dos primeiros mapas individuais, os docentes apresentaram um aperfeiçoamento conceitual, por exemplo, na relação entre o coral e a alga, nas trocas gasosas, na inserção do homem no meio, nas relações entre os componentes vivos e não vivos e quanto aos perfuradores e formadores, embora os conceitos mais abstratos (fotossíntese e transferência de energia) tenham permanecido desarticulados. Isto mostra que a intervenção empregada na oficina pedagógica durante este estudo foi eficaz, pois favoreceu aos docentes perceberem as lacunas e falhas ocorridas na construção dos primeiros mapas e a repensarem o que poderiam ter feito (ou não) e em que poderiam melhorar na construção do mapa final coletivo.

As lacunas conceituais e as dificuldades de relação entre os conceitos, mais evidentes no mapa coletivo foram as seguintes: dificuldade de estabelecer as trocas gasosas (entrada e saída de gases); dificuldades no estabelecimento da relação entre o coral e a alga (simbiose); desconhecimento dos perfuradores que auxiliam a formação dos recifes e dos demais formadores como o banco de arenito e a alga calcária melobesiácea. Além disso, o homem é apresentado como aquele que apenas usufrui e destrói o ecossistema e não como aquele que faz parte do meio e com ele interage.

É interessante que reflitamos: se o homem se alimenta, respira, troca gases e auxilia na reciclagem da matéria, por quê, na visão dos professores, ele não está inserido no ecossistema? É quando transparece, fortemente, a visão antropocêntrica e naturalista de que o homem é um indivíduo à parte do meio ambiente e que os recursos advindos do ecossistema estarão sempre ao seu dispor, para que o usufruam e degradem. 


\section{ENTREVISTA FINAL}

Por intermédio da análise das respostas obtidas na entrevista final pudemos detectar a importância atribuída, pelos docentes, às entrevistas, aos MC e à aula de campo, por ajudarem na percepção das lacunas (e/ou inconsistências na compreensão) que tinham sobre os ambientes recifais e na identificação de possíveis inadequações em sua prática pedagógica.

D1 percebeu que trabalhava os conceitos de forma fragmentada e desarticulada e que isto era fruto da formação recebida e dos livros em que estudou. Considerou que o trabalho realizado na formação continuada o ajudou a articular e conectar melhor os conceitos e que pode mudar um pouco sua prática. D2 ressalta que o mapa e a oficina lhe ofereceram uma visão nítida de como seu trabalho em sala de aula vem sendo desenvolvido de forma fragmentada, sem uma sequência. Nesse sentido, o ajudou a perceber falhas e lacunas na sua compreensão e na sua prática. D3 igualmente mencionou que as atividades vivenciadas instigaram à reflexão sobre o conteúdo ambientes recifais e que pensa desenvolvê-las em sua sala de aula. Afirma também que conseguiu entender melhor o assunto.

Quanto à possibilidade de os MC instigarem a reflexão sobre as particularidades do ecossistema recifal (ações degradantes provocadas pelo homem e sua importância ecológica), D1 afirmou que apenas durante a construção do segundo mapa (coletivo) ao compará-lo com o mapa individual, percebeu suas lacunas. No primeiro mapa excluiu alguns conceitos e, após a aula de campo e da construção do segundo mapa, percebeu as relações existentes entre o ambiente recifal, o homem, a cadeia alimentar e a degradação, ou seja, concluiu que todos os conceitos deveriam estar articulados. Semelhante foi o depoimento de D2:

\section{Não imaginava como esses ambientes são importantes para os seres vivos que vivem diretamente no ecossistema e também a sua importância na participação e contribuição para o equilíbrio ou desequilíbrio. Não imaginava isso e por estar de fora desses ambientes pensava que a parcela de contribuição desses ambientes era pequena, mas na verdade é, ecologicamente, muito grande, todos se integrando (D2).}

A partir do momento em que tiveram a oportunidade de construir seus próprios mapas conceituais, discutir suas produções, vivenciar a aula prática e reconstruir os mapas, coletivamente, os professores foram instigados a pensar nas relações entre os conceitos envolvidos no estudo dos ambientes recifais e sobre a forma como estavam conduzindo as suas aulas. Foram unânimes em afirmar que mudariam as suas aulas e que não fariam mais do mesmo jeito. Isto sugere que reconheceram as suas falhas enquanto prática pedagógica bem como as próprias lacunas com relação ao conteúdo específico.

Sobre o papel das entrevistas, disseram os professores:

Claro, ficamos com uma visão diferente. Se fôssemos comparar as respostas, você iria perceber. Essa primeira entrevista deu aquele estalo para mudar alguma coisa, depois que fizemos a oficina, o mapa, conseguimos perceber muita coisa (D2).

O mapa conceitual foi o instrumento que mais "marcou" os participantes da pesquisa tanto devido a percepção das próprias falhas no conteúdo específico, quanto às dificuldades na articulação dos conceitos, ambas detectadas através deles. Dois dos docentes da pesquisa além de afirmarem que o utilizariam em sala de aula, já o aplicaram durante as suas aulas no decorrer desta pesquisa (D2 numa turma de Ciências estudando sistema digestório e D3 numa turma de matemática, estudando frações). No entanto, D1 vê dificuldades na sua aplicação, conforme pode ser observado no relato a seguir: 
Dependendo do contexto, dependendo do tempo... porque é difícil usar. $\dot{E}$ um trabalho longo que não se faz em 40 ou 50 minutos de aula, teríamos que ter mais tempo para trabalhar. Em uma turma do ensino fundamental e médio é possivel fazer isso, mas de forma partida porque iria passar um mês para fazer, não conseguiria fazer em uma semana, então é o tempo que vai atrapalhar... impedir de trabalhar com esses mapas [...] Não estudaria mais separado, como antes.... Eu iria agora, agregar, juntar e mostrar o que acontece com a degradação ambiental, e que vai afetar o ambiente recifal e esse ambiente recifal afetado como vai repercutir para o homem (D1).

A não compreensão do conteúdo, de forma sistêmica pelo professor repercute, inevitavelmente, em sua prática pedagógica. Ao perceber lacunas na própria formação e procurar saná-las o professor estará dando o primeiro passo para perceber falhas na sua prática pedagógica e tentar reorientá-la. Necessita, ele próprio, mudar e se aprofundar de forma contextualizada e sistêmica no conteúdo. E, para desenvolver no estudante, sensibilidade e mudança de atitude diante das agressões ambientais realizadas pelo homem, o professor necessita, ele próprio, mudar a sua atitude e, consequentemente, a sua prática pedagógica.

Mas o que significa isto na prática? D1 percebeu uma fragmentação no seu trabalho e afirma que agora vai tentar associar os conceitos. Percebeu também as ações antrópicas sobre os ambientes recifais e o retorno dessas ações para o homem. No entanto, o fato de afirmar que pretende "mostrar" sugere uma postura tradicional, expositiva que não sinaliza para uma problematização que instigue o educando a refletir e mudar de atitude.

Na opinião de D2, o aluno perceberá, de fato, o que é um ecossistema, os fatores que estão envolvidos neste ecossistema e a biodiversidade existente, através de uma aula de campo, pois a mesma oportunizaria ao aluno vivenciar de forma concreta o que ele vê, teoricamente, nos livros. No entanto, o fato de vivenciar uma aula de campo não garante uma mudança de atitude, nem a sensibilidade e nem a reflexão acerca dos fatores agressivos provocados pelo homem nesses ambientes, embora possa favorecer e contribuir para o aprendizado do conteúdo específico.

Todos concordaram com a importância dos mapas conceituais para a compreensão sistêmica dos ambientes recifais. No entanto, constatamos que esta compreensão só foi possível, após a aula de campo e a construção do segundo mapa. Salientaram, também, que a aula de campo favoreceu o aprofundamento conceitual. D3 afirmou que durante essa vivência compreendeu melhor que "estava dentro daquele ambiente". Os mapas ajudaram os docentes a pensar de forma articulada e contextualizada, pois em quase todos os momentos da entrevista os mesmos descreveram a importância dessas articulações e a necessidade das mesmas.

\section{QUESTÕES RELACIONADAS ÀS CONCEPÇÕES DE EA E DE AMBIENTES RECIFAIS E ÀS PRÁTICAS DE EA.}

Os docentes tiveram a oportunidade de vivenciar um ecossistema e suas peculiaridades durante a aula de campo e isto foi extremamente relevante para perceberem a grandiosidade do ecossistema recifal. No que concerne às concepções sobre os ecossistemas recifais, os professores reconhecem uma mudança na sua compreensão sobre o tema:

Eu acho que mudou. Quando a gente observava um ambiente a gente só se ligava na paisagem, não via aquilo como um ecossistema e que tem vida (D2). 
A partir do momento que eu montei o primeiro mapa eu separei os componentes bióticos e abióticos e pude ver, depois da aula prática, depois da construção coletiva, que um tá ligado ao outro e ligado àquele ecossistema. Mudou a minha concepção, eu penso diferente (D3).

A falta de tempo constitui-se numa das principais dificuldades para o desenvolvimento de trabalhos efetivos em EA, prejudicando a execução adequada do planejamento pedagógico e o aperfeiçoamento profissional.

Se durante a construção dos mapas, D1 não reconheceu as ações antrópicas indiretas e não as distinguiu das diretas, pode estar agredindo o ambiente de modo indireto. Por não perceber que a EA vai além da concepção antropocêntrica e utilitarista de "cuidar para não perder" e por não distinguir as ações diretas das indiretas, possivelmente não desenvolverá uma prática pedagógica efetiva, uma vez que transparece não saber qual é a finalidade da EA.

D2 também apresenta uma visão naturalista. Salienta que sempre teve o cuidado de colocar o lixo de seu consumo no lugar certo, dando a entender que são as ações diretas as únicas responsáveis pelos problemas ambientais. Ao comentar sobre "a imagem da tartaruga comendo um saco plástico de picolé" se deu conta das consequências graves que seus atos poderiam ter sobre o meio ambiente e sobre a biodiversidade. Estes fatos demonstram que tanto a aula de campo quanto as construções dos mapas, levaram o docente a perceber o quanto é profundo e complexo o resultado de nossas ações sobre esses ecossistemas e que muitas vezes não temos consciência.

Esperamos que a percepção articulada do professor, da imensidão dos prejuízos provocados pelo homem gere uma prática pedagógica efetiva que venha consequentemente a sensibilizar seus alunos.

\section{CONSIDERAÇÕES FINAIS}

Os resultados apresentados apontam para a necessidade de um cuidado especial com a formação docente. Em referência ao saber disciplinar, os professores de Biologia apresentaram lacunas conceituais e, consequentemente, dificuldades de articulação entre os conceitos e processos ocorrentes no ecossistema ambientes recifais. Se os docentes apresentaram dificuldade no conteúdo disciplinar possivelmente esta dificuldade deve-se à fragilidade na sua formação acadêmica, aos processos curriculares vivenciados e em sua experiência como estudante em formação.

Este fato é preocupante porque são estes os docentes que hoje ministram as suas aulas na educação básica, formando cidadãos e muitas vezes futuros docentes. O que queremos para as próximas gerações? Queremos indivíduos pensantes, atuantes, colaborativos e críticos diante dos problemas planetários, ou não? Os ambientes recifais são sistemas complexos e que requerem uma compreensão sistêmica e contextualizada.

Nesse sentido e com base nesse viés, Capra (1996) salienta que quanto mais estudamos os principais problemas de nossa época, mais somos levados a perceber que eles não podem ser entendidos isoladamente. São problemas sistêmicos, o que significa que estão interligados e são interdependentes. Na construção do mapa coletivo os docentes perceberam que não compreenderiam se não fizessem as devidas articulações, se não pensassem nesses ambientes e em suas relações de forma conjunta, ou seja, "juntando".

É fundamental que a formação dos professores seja problematizadora, fomente a criticidade e a reflexão, provocando mudanças conceituais e procedimentais, desta forma preparando-os para desenvolver práticas pedagógicas emancipatórias com este mesmo viés e 
desenvolvendo, nos educandos, aptidões para atuar nesta realidade sócio-histórico-culturalambiental.

\section{REFERÊNCIAS}

AMARAL, F. D. et al. Cnidarians of Saint Peter and St. Paul Archipelago, Northeast Brazil. In: 10 International Coral Reef Symposium. Proceedings.., v.1, 2002a. p. 567-572.

AMARAL, F. D.et al. Corais e hidrocorais de alguns ambientes recifais de Pernambuco. In: Congresso Brasileiro de Zoologia, 24, 2002 b, Itajaí. Resumos... Itajaí.. 2002b, p 22.

AMARAL, F. M. D. et al. Atividades de extensão do Laboratório de Ambientes Recifais (LAR/UFRPE). In: Congresso Brasileiro de Extensão Universitária, 1, 2003, João Pessoa. Anais... João Pessoa: EDUFPB, 2003. p.1-8.

BEHRENS, M. A. A prática pedagógica e o desafio do paradigma emergente. Revista Brasileira de Estudos Pedagógicos, v. 80, n. 196, 1999, p. 383-403.

BEHRENS, M. A. O paradigma emergente e a prática pedagógica. Petrópolis: Vozes. 2005, 117p.

BONOTO, D. M. B. et al. Educação Ambiental e o trabalho com valores reflexões sobre experiências de formação continuada. Revista Educação - Teoria e prática, vol. 10, n. 18 e n. 19, 2002, p. 67-71. Disponível em: <cecemca.rc.unesp.br> Data de acesso: 06 abr 2009.

BRASIL. Constituição da Repúbica Federativa do Brasil de 1988. Capítulo VI - Art. 225. Disponível em: http://www.planalto.gov.br/ccivil_03/constituicao/constitui\%C3\% A7ao.htm> Data de acesso: 10 jul. 2012.

CANDAU, V. M. Da didática fundamental ao fundamental da didática. In: ANDRE, M. e OLIVEIRA, M. R. (Org.) Alternativas no ensino de didática, 2 ed. Papirus, 2000, p. 71-95.

CAPRA, F. A Teia da vida: uma nova compreensão científica dos sistemas vivos. São Paulo: Cultrix, 1996. 256p.

CARNEIRO-LEÃO, A. M. A. et al. Ensinando Biologia numa perspectiva de complexidade. In: JÓFILI, Z.; ALMEIDA, A. (Org.) Ensino de Biologia, meio ambiente e cidadania: olhares que se cruzam. Recife: UFRPE: SBenBio/Regional 5,. 2009, p. 197-206.

CARVALHO, I. C. M. Educação ambiental crítica: nomes e endereçamentos da educação. In: LAYRARGUES, P. P. (Coord.) Identidades da Educação Ambiental Brasileira. Ministério do Meio Ambiente. Diretoria de Educação Ambiental. Brasília: MMA, 2004a. 156p.

FREIRE, P. Pedagogia da autonomia: saberes necessários à prática educativa, 25 ed. São Paulo: Paz e Terra, 1996. 165p.

GOULART, M. \& CALLISTO, M. Bioindicadores de qualidade de água como ferramenta em estudos de impacto ambiental. Revista da FAPAM, ano 2, n. 1, 2003. 9p.

GUIMARÃES, M. A Educação Ambiental crítica. In: LAYRARGUES, P. P. (Coord.) Identidades da Educação Ambiental Brasileira. Ministério do Meio Ambiente. Diretoria de Educação Ambiental. Brasília: MMA, 2004. 156p.

JÓFILI, Z. Pedagogia crítica freireana e a formação de professores. In: (Org.) Aprimorando-se com Paulo Freire... no que fazer educativo. Recife: Bagaço. (Coleção Paulo Rosas, vol 3). 2006, p. 47-67.

LOUREIRO, C. F. B. Educação ambiental transformadora. In: (Coord.) Identidades da Educação Ambiental Brasileira. Ministério do Meio Ambiente. Diretoria de Educação Ambiental. Brasília: MMA, 2004. 156p.

LOUREIRO, C. F. B; LAYRARGUES, P. P.; CASTRO, R. S. (Orgs.). Pensamento complexo, dialética e Educação Ambiental. 2. ed. São Paulo: Cortez, 2011. 213p. 
MEDINA, N. M. \& SANTOS, E. C. Educação Ambiental: uma metodologia participativa de formação, 3 ed. Petrópolis, RJ: Vozes. 1999. 231p.

MELO, R. S.; CRISPIM, M. C.; LIMA, E. R. V. Turismo em ambientes recifais: em busca da transição para a sustentabilidade. Caderno virtual de turismo, vol 5, n. 4, 2005. p. 1-9.

NOVAK, J. D.; CAÑAS, A. J. A teoria subjacente aos mapas conceituais e como elaborá-los e usálos. Práxis Educativa, Ponta Grossa, v.5, n.1, jan.-jun. 2010 p. 9-29. Disponível em: $<$ http://www.periodicos.uepg.br $>$ Data de acesso: 08 out. 2011.

NÓVOA, A. (Org.) Vidas de professores, 2 ed. Portugal. Ed: Porto, 1995. 215p.

OLIVA, J. T. A Educação Ambiental no ensino formal. Congresso brasileiro de qualidade na educação. MARFAN, M. (Org.). Brasília, vol. 3. MEC, SEF, 2002. p. 41-48.

REIGOTA, M. A floresta e a escola. 2 ed. São Paulo: Cortez, 2002. 167p.

RUPPERT, E. E.; BARNES, R. D. Zoologia dos Invertebrados, 6. ed. São Paulo: Ed. Roca, 1996. $1028 \mathrm{p}$.

SORRENTINO, M. De Tbilisi a Thessalonik: a Educação Ambiental no Brasil. In: QUINTAS, J. S. (Org.). Pensando e praticando a Educação Ambiental no Brasil. Brasília: Ibama, 2002. 